Jurnal Indonesia Sosial Teknologi: p-ISSN: 2723 - 6609

e-ISSN : 2745-5254

Vol. 2, No. 7 Juli 2021

\title{
PERANCANGAN SISTEM INFORMASI PENJUALAN HANDPHONE DI FORZA MUFID PERDANA SELULAR
}

\author{
Atra Alukadinata ${ }^{1}$, Muhammad Firdaus ${ }^{2}$, dan Rifki Ristiawan ${ }^{3}$ \\ ${ }^{1,2,3}$ Program Studi Teknik Informatika, Fakultas Teknik dan Ilmu Komputer, Universitas \\ Indraprasta PGRI. \\ Email : atraaluka13@gmail.com ${ }^{1}$, dasurichi@gmail.com², rifki2889@gmail.com³
}

\begin{abstract}
Abstrak
Seiring berkembangnya ilmu pengetahuan dan teknologi informasi pada masa sekarang ini dirasakan semakin berkembang dengan pesat, salah satu diantaranya adalah di bidang teknologi komputer. Pesatnya pertumbuhan ilmu pengetahuan teknologi khususnya di bidang komputer disetiap aspek kehidupan dan penggunaan teknologi komputer dan teknologi komunikasi yang menghasilkan sebuah penggabungan sistem informasi yang saat ini mudah untuk di akses tanpa adanya batasan waktu dan jarak dengan menggunakan jaringan internet. Model penjualan atau bisnis ikut terpengaruh dari perkembangan ilmu pengetahuan teknologi tersebut, terlebihnya dengan pesatnya pertumbuhan pengguna internet di berbagai belahan dunia khususnya negara berkembang. Forza Mufid Perdana Selular adalah toko handphone yang menjual bermacam-macam pheriperal handphone, asesoris, handphone serta service handphone dan masih menggunakan sistem manual. Dari latar belakang tersebut diatas maka akan dibuat aplikasi yang dapat membantu dalam penjualan dan stok barang di Forza Mufid Perdana Selular. Aplikasi ini juga terdapat menu stok opname untuk menginputkan data barang dengan tujuan bisa memudahkan para pegawai untuk mengecek stok yang ada. Dengan adanya permasalahan diatas sehingga penulis tertarik untuk membuat Tugas Akhir dengan judul: "Perancangan Sistem Informasi Penjualan Handphone Di Forza Mufid Perdana Selular".
\end{abstract}

Kata kunci: sistem informasi; aplikasi penjualan; Proses.

\section{Abstract}

Along with the development of science and information technology today, it is felt that it is growing rapidly, one of which is in the field of computer technology. The rapid growth of technological science, especially in the field of computers, in every aspect of life and the use of computer technology and communication technology, has resulted in a merging of information systems that are currently easy to access without any time and distance restrictions using the internet network. The sales or business model is also influenced by the development of technology science, especially with the rapid growth of internet users in various parts of the world, especially developing countries. Forza Mufid Perdana Selular is a mobile phone shop that sells a variety of cellphone peripherals, accessories, cellphones and cellphone services and still uses a manual system. From the background above, an application will be made that can assist in the sale and stock of goods at Forza 
Mufid Perdana Selular. This application also has a stock opname menu to input data items with the aim of making it easier for employees to check existing stocks. With the above problems, the authors are interested in making a final project with the title: "Perancangan Sistem Informasi Penjualan Handphone Di Forza Mufid Perdana Selular".

Keywords : information system; sales application; procces.

\section{Pendahuluan}

Seiring berkembangnya ilmu pengetahuan dan teknologi informasi pada masa sekarang ini dirasakan semakin berkembang dengan pesat, salah satu diantaranya adalah di bidang teknologi komputer. Keberadaan komputer di tengah-tengah kehidupan manusia sekarang ini sudah menjadi komoditas utama (Khoirunnisa \& Kurniawan, 2019: 17). Karena komputer dirasakan dapat menunjang kelancaran pekerjaan yang menuntut kecepatan, keterampilan, keakuratan dan keefisiensian waktu dan tenaga (Yanuarti, 2017: 60).

Komputer merupakan salah satu perangkat yang di dalamnya terdapat perangkat keras (hardware) dan perangkat lunak (software) yang dirancang atau dibuat dengan menggunakan berbagai bahasa pemograman. Komputer diciptakan untuk membantu manusia dalam pemecahan dan penyelesaian masalah (Prabowo \& Syani, 2017). Hal ini disebabkan karena keterbatasan manusia dalam hal kecepatan, ketelitian dan dapat timbulnya rasa lelah atau jenuh dalam melakukan sebuah pekerjaan.

Pesatnya pertumbuhan ilmu pengetahuan teknologi khususnya di bidang komputer disetiap aspek kehidupan dan penggunaan teknologi komputer dan teknologi komunikasi yang menghasilkan sebuah penggabungan sistem informasi yang saat ini mudah untuk di akses tanpa adanya batasan waktu dan jarak dengan menggunakan jaringan internet (Miskahuddin, 2017: 295). Model penjualan atau bisnis ikut terpengaruh dari perkembangan ilmu pengetahuan teknologi tersebut, terlebihnya dengan pesatnya pertumbuhan pengguna internet di berbagai belahan dunia khususnya negara berkembang (Miskahuddin, 2017: 299).

Forza Mufid Perdana Selular adalah toko handphone yang menjual bermacammacam pheriperal handphone, asesoris, handphone serta service handphone. Forza Mufid Perdana Selular merupakan salah satu toko yang proses jual belinya masih menggunakan sistem manual. Pada proses penjualan barang biasanya masih ditulis menggunakan nota manual (Prayoga, Septianzah, \& Puspitasari, 2021). proses mengetahui stok barang digudang juga harus mengecek satu persatu yang disesuaikan dengan catatan. Jadi semua kegiatan transaksi dan jual beli masih menggunakan sistem nota manual (Hasan \& Rahmawati, 2018).

Dari latar belakang tersebut diatas maka akan dibuat aplikasi yang dapat membantu dalam penjualan dan stok barang di Forza Mufid Perdana Selular. Program aplikasi tersebut adalah "Aplikasi penjualan dan stok barang di Forza Mufid Perdana Selular”. Sistem aplikasi penjualan dan stok opname Forza Mufid Perdana Selular ini dibuat dengan menggunakan Bahasa pemograman java dan database mysql. karena 
Bahasa pemograman tersebut sederhana, fleksibel dan efisien (Ahmadian, Mizuardy, \& Ar, 2017: 7). Aplikasi ini diharapkan akan membantu dalam transaksi penjualan, stok barang dan juga laporan penjualan. Aplikasi ini juga terdapat menu stok opname untuk menginputkan data barang dengan tujuan bisa memudahkan para pegawai untuk mengecek stok yang ada. Selain itu, dengan adanya aplikasi ini karyawan toko akan lebih efisien dan maksimal dalam bekerja. Semua transaksi jual beli juga sudah tersimpan dalam computer (Sudirman et al., 2020).

Pada sebuah toko pastinya ingin barangnya dapat terjual dengan lancar dan mendapatkan keuntungan sesuai yang diharapkan, agar usaha dagang tersebut tetap exist dan berkembang, diperlukan strategi dagang dan pengelolaan yang baik (Jamal \& Yulianto, 2013). Strategi penjualan yang dimaksud berupa peningkatan kualitas marketing, manajemen, pelayanan, dan lain-lain termasuk penerapan teknologi informasi di toko tersebut (Priyanto, 2018). Mengenai proses pembayaran konsumen kepada pimpinan melalui petugas kasir, pihak pimpinan mempunyai wewenang dalam proses penerimaan laporan dan pengelolaannya. Petugas kasir bertanggung jawab dalam pembuatan nota transaksi penjualan juga membuat laporan transaksi yang dilakukan dan mengelola adminitrasi keuangan berdasarkan perintah pimpinan.

\section{Metode Penelitian}

Metodologi penelitian yang digunakan adalah penelitian grounded research yaitu suatu metode penelitian yang diawali dari fakta berujuan untuk mengadakan generalisasi empiris menetapkan konsep-konsep membuktikan dan atau mengembangkan teori. Hal-hal yang dilakukan peneliti dalam penelitian ini adalah dengan pengumpulan dan analisis data yang dilakukan pada waktu bersamaan, data yang merupakan sumber teori, serta studi perbandingan untuk menentukan sampai seberapa jauh suatu gejala dan kendala berlaku untuk umum.

Beberapa metode yang digunakan oleh peneliti untuk mengumpulkan data dan informasi mengenai obyek penelitian ini yaitu observasi, dimana peneliti langsung melihat dan mendata proses penilaian mulai dari proses penginputan pendaftaran calon anggota sampai terbentuknya arsip laporan data yang akan delaporkan kepada kepala sekolah setiap semesternya. Observasi dilakukan selama 3 bulan yaitu dari tanggal 01 Juni 2020 sampai dengan 31 Juni 2020. Metode pengumpulan data, dimana aktivitas ini melakukan pengumpulan data dengan studi lapangan dan pengambilan dari beberapa bahan pustaka yang dapat dijadikan bahan referensi suatu sistem yang akan dianalisa dan dibahas dalam topic ini, penulis melakukan pengumpulan data dengan beberapa metode penelitian. Metode penelitian merupakan cara ilmiah untuk mendapatkan data dengan tujuan dan kegunaan tertentu.

Dengan menguasai metode penelitian, bukan hanya memecahkan masalah tetapi dapat mengembangkan beberapa bidang keilmuan. Oleh karena itu ada beberapa metode penelitian yang dilakukan serta wawancara dengan pihak narasumber. Aktivitas ini peneliti melakukan wawancara langsunng dengan petugas atau sales counter untuk memperoleh informasi yang dibutuhkan dan mengajukan pertanyaan yang ada 
hubungannya dengan permasalahan yang diteliti. Langkah-langkah dalam perancangan aplikasi ini, peneliti menggunakan metode waterfall model (model air terjun), dimana setiap langkah atau tahapannya harus diselesaikan terlebih dahulu sebelum lanjut ke tahap selanjutnya, tanpa ada pengulangan ke tahapan sebelumnya.

\section{Hasil Dan Pembahasan}

Toko Forza Mufid Perdana Seluler merupakan sebuah sarana tempat untuk melakukan transaksi jual - beli handphone secara tunai maupun kredit, jenis usaha ini merupakan wiraswasta yang termasuk golongan Usaha Kecil Menengah (UKM) yang dirancang untuk melayanai transaksi jual - beli handphone secara langsung dan saling berhadapan antara pelanggan dengan pelayan di toko yang jika pelanggan datang ke toko dan sudah melakukan transaksi maka barangpun dapat langsung dibawa pulang dan tak perlu menunggu dengan lebih lama lagi. Beda halnya dengan sistem transaksi online yang tidak dapat melihat barangnya secara langsung sebelum terjadinya transaksi jual-beli, pelanggan tidak mengenal penjual karna tidak berhadapan dan melihat secara langsung bagaimana orang yang menjual barangnya tersebut (Barkatullah, 2017). Dan cara transaksinya dilakukan dengan sistem pembayaran transfer, lalu pembeli harus menunggu pesanan tersebut sampai tiba di tujuan.

Penjualan adalah salah satu kegiatan yang terpenting dalam sebuah perusahaan dan merupakan sumber pendapatan utama bagi kelangsungan perusahaan (Hartono, Hutomo, \& Mayangsari, 2012). Berbagai kiat dilakukan dalam usaha untuk mencapai tingkat penjualan yang diharapkan. Saat ini proses bisnis yang sedang berjalan di toko Forza Mufid Perdana Seluler belum terkomputerisasi. Kegiatan yang dilaksanakan menyangkut bidang penjualan handphone pada toko ini, diantaranya : 1. Melayani Konsumen, 2. Proses Pencatatan Transaksi Penjualan, 3. Pemasukan stok, 4. Laporan Penjualan.

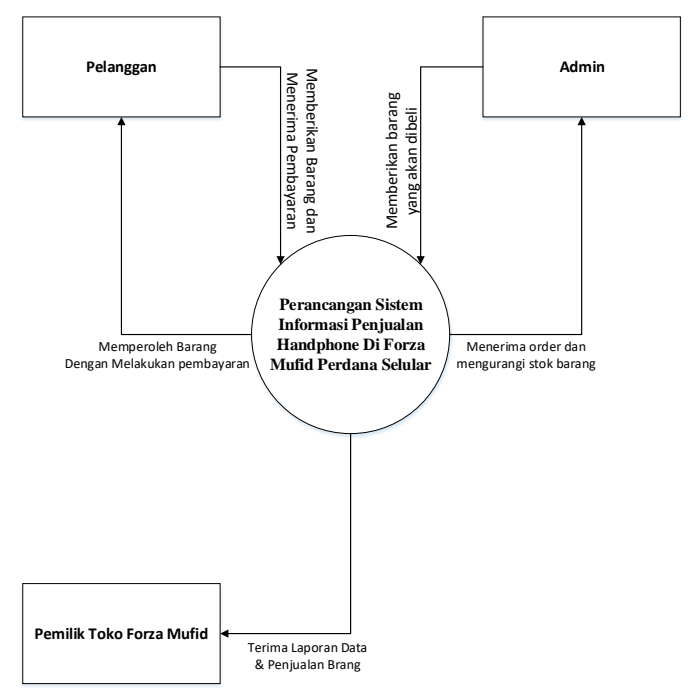

Gambar 1. Diagram Konteks Sistem Berjalan. 
Berdasarkan masalah-masalah yang dihadapi dalam sistem penjualan handphone pada Toko Forza Mufid Perdana Selular, maka penulis memberikan alternatif penyelesaian masalahnya yaitu berupa perancangan sistem yang terkomputerisasi bisa lebih memudahkan dalam kegiatan penjualan handphone, dapat menambah keterangan stok barang yang tersedia dan pembuatan laporan transaksi penjualan pada toko Iraphone akan menjadi lebih aman dan kondusif.

Berikut dibawah ini diagram DFD (Data Flow Diagram) yang menggambarkan usulan skema alur data dari Pelanggan ke Admin, kemudian Admin mengirimkan laporan data barang ke Pemilik Toko.

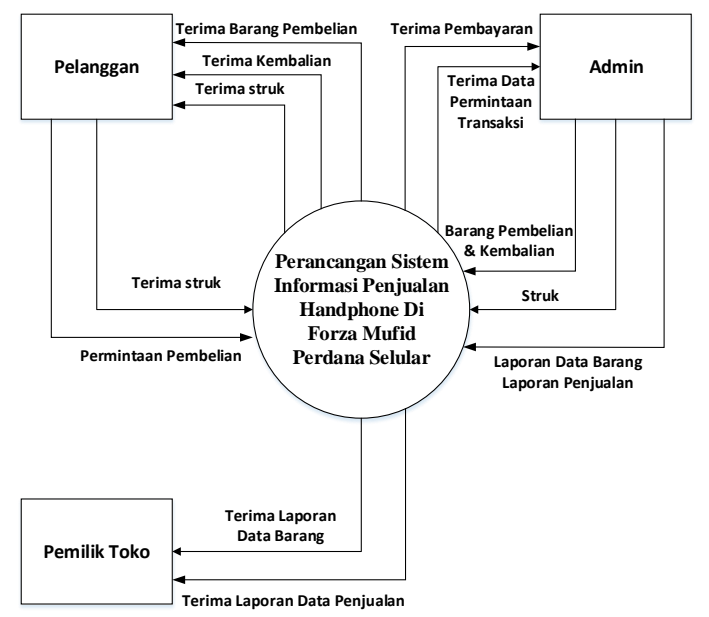

Gambar 2. Diagram Konteks Sistem Berjalan yang Diusulkan.

Ada aturan bisnis sistem pada Toko Forza Mufid Perdana Selular yang akan diusulkan oleh penulis adalah sebagai berikut: 1 . Pemilik toko harus memberikan data barang kepada bagian administrasi toko untuk diinput jumlah barang yang masuk, 2 . Karyawan yang melayani pelanggan harus mengarahkan pada bagian administrasi untuk diproses permintaan barang yang telah disetujui, 3. Bagian administrasi menginput data pembelian barang dan membuatkan struk penjualan untuk diserahkan kepada pelanggan, 4. Setelah menginput data penjualan barang, lalu staf admin mengecek barang yang sudah terjual dan membuatkan laporannya, 5. Bagian administrasi membuatkan laporan transaksi penjualan setiap harinya yang sudah terinput pada komputer dan melaporkannya kepada pemilik usaha untuk dicek dan pembelian barang kembali, 6 . Pemilik usaha menerima dan mengecek laporan hasil transaksi penjualan dan membelanjakan kembali jika ada barang yang kosong untuk diinput dan disediakan oleh bagian administrasi.

Antarmuka menu utama ini berisi menu-menu yang terletak dalam menu utama yang berada pada bagian menu bar dan toolbar, yang didalamnya terdapat sub-sub menu. Pada menu home ini hanya terdapat sebuah gambar instansi. 


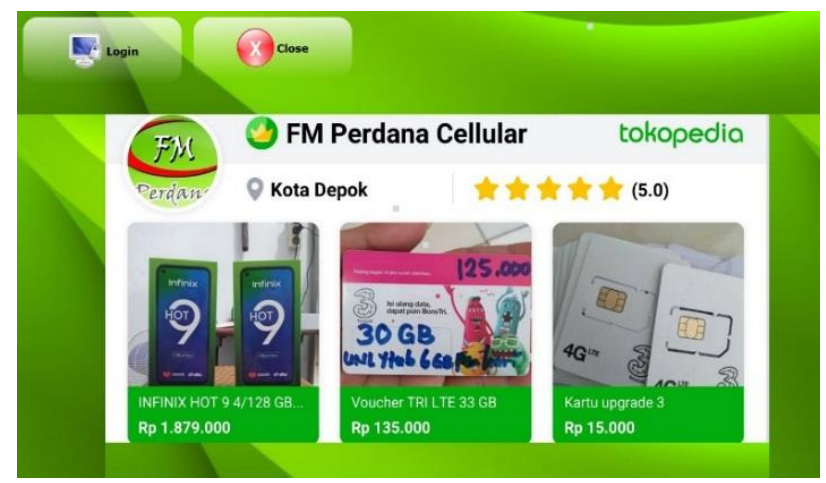

Gambar 3. Antar Muka Halaman Depan.

Antarmuka menu login ini yaitu digunakan untuk masuk ke menu utama supaya bisa mengakses menu yang ada di dalam form utama. Dalam antarmuka form login ini berisi logo optik atau instansi, kolom nama pengguna, kata sandi dan ada juga tombol login yang digunakan untuk mengecek apakah nama dan kata sandi sudah benar, untuk digunakan masuk ke halaman utama.

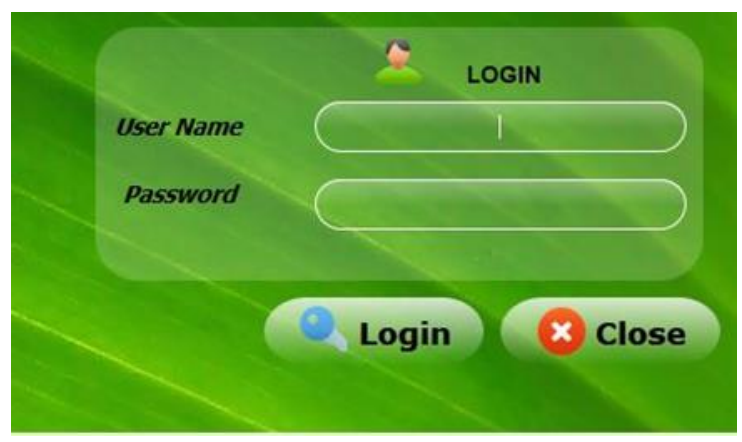

Gambar 4. Desain Form Login.

Pada antarmuka ini, merupakan antamuka yang didalamnya terdapat sebuah form untuk mengelola data barang, seperti menyimpan dan mengedit.

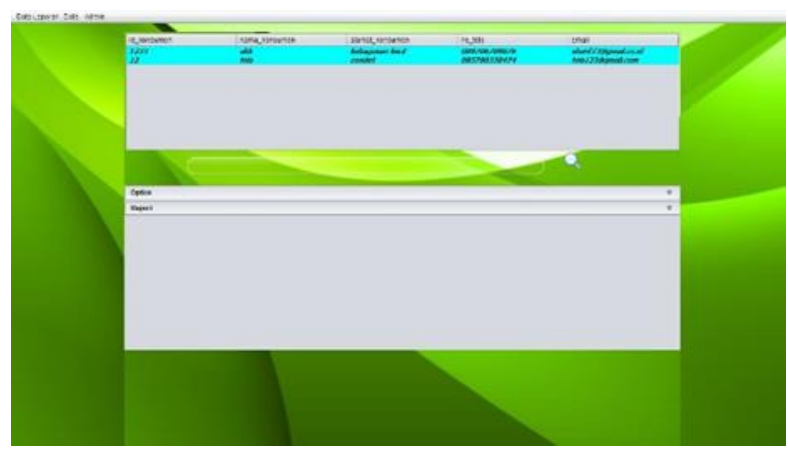

Gambar 5. Desain Form Data Barang.

Pada antarmuka ini, merupakan antamuka yang didalamnya terdapat sebuah form untuk mengelola data pelanggan, seperti menyimpan dan mengedit. 
Atra Alukadinata ${ }^{1}$, Muhammad Firdaus ${ }^{2}$, dan Rifki Ristiawan ${ }^{3}$

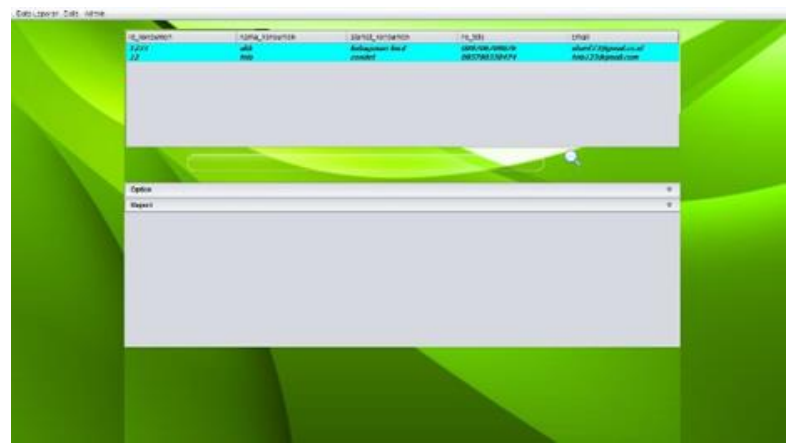

Gambar 6. Desain Form Data Pelanggan.

Pada antarmuka ini, merupakan antamuka yang didalamnya terdapat sebuah form untuk mengelola data penjualan, seperti menyimpan dan mengedit.

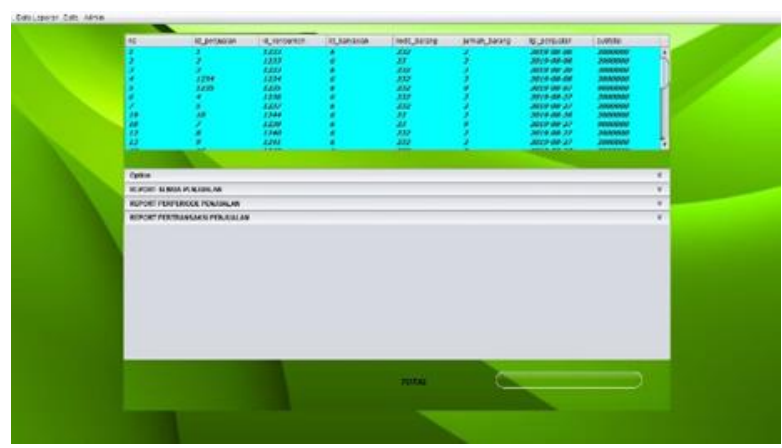

Gambar 7. Desain Form Data Penjualan.

Halaman Home merupakan halaman utama dari Sistem Informasi Kasir Berbasis Client Server. Halaman ini berfungsi sebagai tempat untuk menampilkan informasiinformasi tentang Sistem ini.

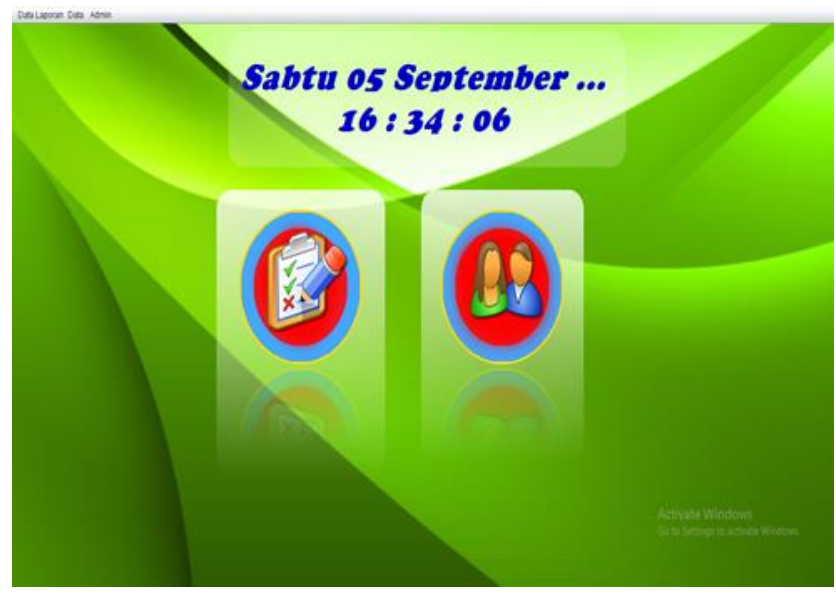

Gambar 8. Tampilan Halaman Utama. 
Implementasi halaman data barang merupakan form yang berisi data barang. Halaman data barang adalah inputan awal dalam sistem yaitu dengan cara memasukkan data barang sesuai kriteria yang harus di isi.

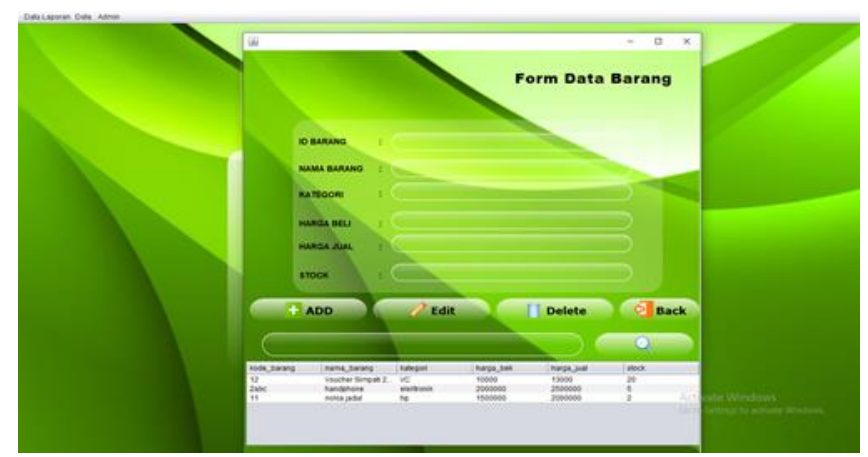

Gambar 9. Tampilan Data Barang.

Halaman penjualan merupakan bagian transaksi yang digunakan untuk menghitung data penjualan barang.

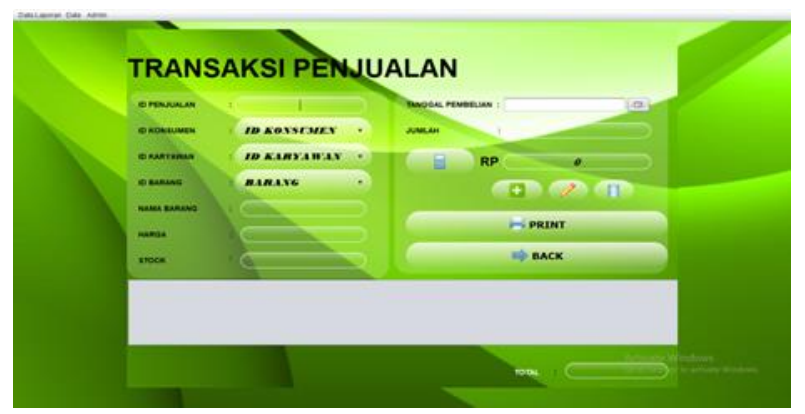

Gambar 10. Tampilan Data Penjualan.

Pada halaman laporan ini menampilkan laporan sesuai dengan tanggal yang sudah ditentukan pada inputan Filter tanggal, berikut tampilan laporan. Dibawah ini merupakan halaman form yang menampilkan stok barang yang tersedia.

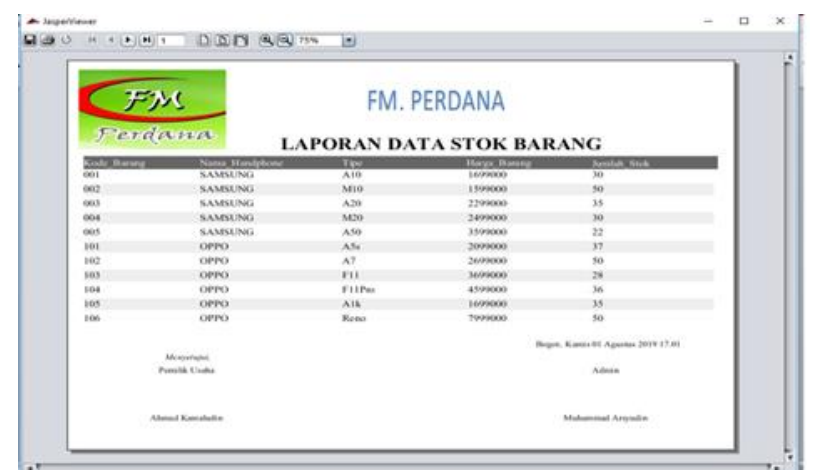

Gambar 11. Laporan Persediaan Barang.

Pada halaman laporan dibawah ini menampilkan laporan struk bukti transaksi sesuai kegiatan transaksi pada satu waktu. 
Atra Alukadinata ${ }^{1}$, Muhammad Firdaus ${ }^{2}$, dan Rifki Ristiawan ${ }^{3}$

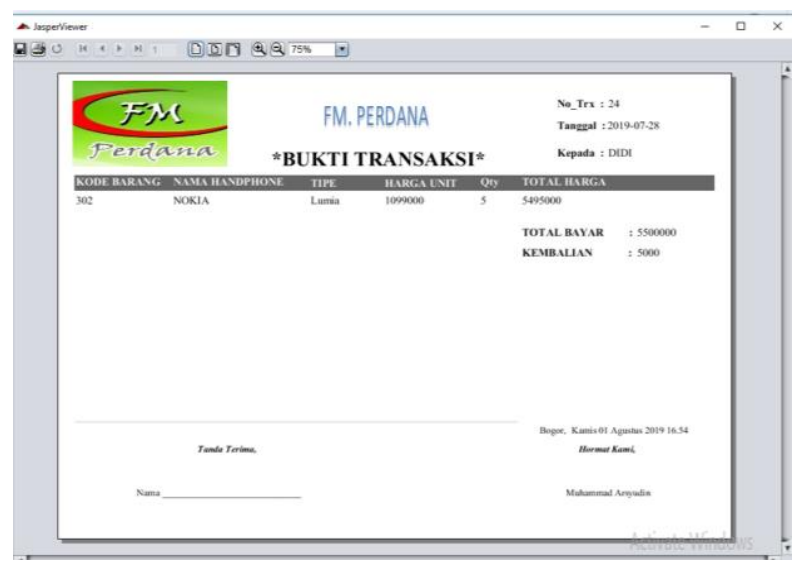

Gambar 12. Laporan Bukti Transaksi.

Pada halaman laporan dibawah ini menampilkan laporan struk bukti transaksi sesuai kegiatan transaksi setiap harinya.

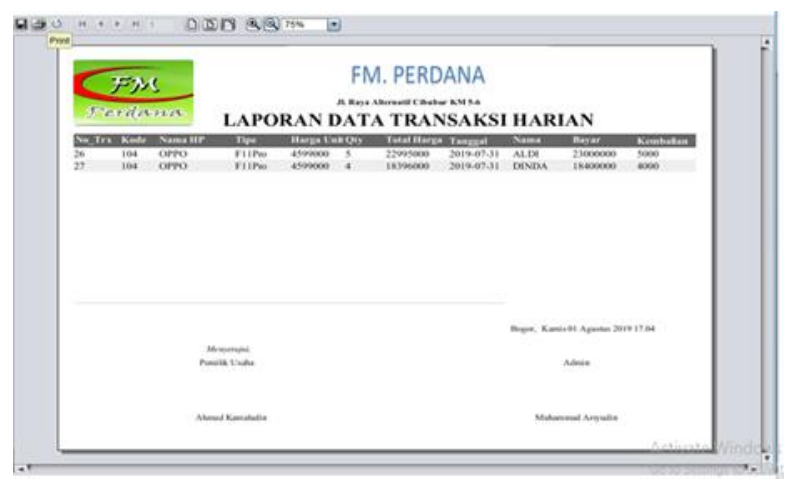

Gambar 13. Laporan Data Transaksi Harian.

Pada tampilan layer dibawah ini juga berfungsi untuk menampilkan laporan transaksi yang sudah terjadi pada setiap permintaan bulannya. Pada menu diatas berbeda dengan laporan data transaksi keseluruhan yang menampilkan semua transaksi yang sudah terjadi, tetapi hanya menampilkan keluaran perbulannya saja sesuai yang dibutuhkan oleh admin agar dapat mempermudah dalam membuat laporan bulanannya.

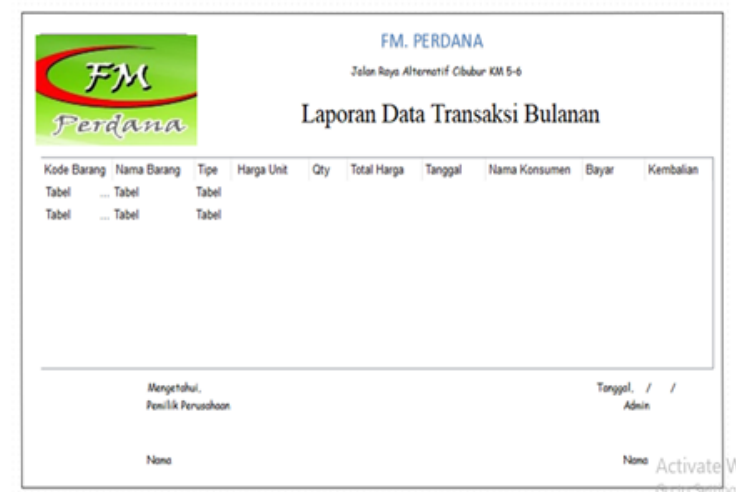

Gambar 14. Laporan Data Transaksi Bulanan. 


\section{Kesimpulan}

Penelitian kami tersebut telah menghasilkan sistem informasi aplikasi kasir berbasis client-server pada studi kasus di Forza Mufid Perdana Selular. Dengan dibuatnya aplikasi penjualan ini berdasarkan hasil penelitian dan analisis permasalahan yang terjadi, maka dapat di ambil kesimpulan bahwa perancangan aplikasi Penjualan ini dapat membantu kinerja dan pelayanan di Forza Mufid Perdana Selular tersebut dapat menjadi lebih efektif, cepat, serta pengolahan data dapat dikontrol dengan mudah. Aplikasi penjualan ini pun diharapkan dapat membantu proses pendataan barang dan membantu kasir maupun petugas Forza Mufid Perdana Seluler mengefisienkan waktu dalam membuat laporan laba yang dibutuhkan. Penulis juga menyarankan untuk kedepannya aplikasi penjualan ini dapat dikembangkan lagi, agar dapat berguna bagi Forza Mufid Perdana Seluler kedepannya.ditambahkan saran atau tahapan kegiatan selanjutnya. 
Atra Alukadinata ${ }^{1}$, Muhammad Firdaus $^{2}$, dan Rifki Ristiawan ${ }^{3}$

\section{Blibliografi}

Ahmadian, Hendri, Mizuardy, Hendi, \& Ar, Khairan. (2017). MAHIR PEMROGRAMAN VISUAL DENGAN JAVA. UNIMAL PRESS.

Barkatullah, Abdul Halim. (2017). Hukum Transaksi Elektronik di Indonesia sebagai Pedoman dalam Menghadapi Era Digital Bisnis E-Commerce di Indonesia. Nusa Media.

Hartono, Hendry, Hutomo, Karyana, \& Mayangsari, Marshelia. (2012). Pengaruh Strategi Pemasaran Terhadap Peningkatan Penjualan Pada Perusahaan" Dengan Menetapkan Alumni Dan Mahasiswa Universitas Bina Nusantara Sebagai Objek Penelitian. Binus Business Review, 3(2), 882-897.

Hasan, Muhammad Faisal, \& Rahmawati, Diana. (2018). Perancangan Sistem Akuntansi Penjualan Tunai Dan Pembelian Tunai Terkomputerisasi Pada Usaha Kuliner Cafe The Milk Boyolali. Jurnal Profita: Kajian Ilmu Akuntansi, 6(1).

Jamal, Ahmad, \& Yulianto, Lies. (2013). Rancang Bangun Sistem Informasi Aplikasi Kasir Menggunakan Barcode Reader Pada Toko Dan Jasa Widodo Computer Ngadirojo Kabupaten Pacitan. Speed-Sentra Penelitian Engineering Dan Edukasi, $5(3)$.

Khoirunnisa, Lia, \& Kurniawan, Fachrul. (2019). Sistem Informasi Geografis Pemetaan Komoditas Pertanian dan Informasi Iklim Berbasis Slim Framework. Sains, $\begin{array}{lllll}\text { Aplikasi, } \quad \text { Komputasi Dan Teknologi Informasi, } & \text { 1(1), } & 16 .\end{array}$ https://doi.org/10.30872/jsakti.v1i1.2260

Miskahuddin, Miskahuddin. (2017). Pengaruh Internet Terhadap Penurunan Minat Belajar Mahasiswa. Jurnal MUDARRISUNA: Media Kajian Pendidikan Agama Islam, 7(2), 293. https://doi.org/10.22373/jm.v7i2.2366

Prabowo, Faizal Ari, \& Syani, Mamay. (2017). Sistem Informasi Pengolahan Sertifikat Berbasis Web Di Divisi Training Seamolec. Jurnal Masyarakat Informatika Indonesia, 2(1), 73-81.

Prayoga, Prayoga, Septianzah, Kevin, \& Puspitasari, Anggun Citra Dini Dwi. (2021). Pembangunan Sistem Inventory Dan Penjualan Toko Distributor Sunflower Raincoat Menggunakan Java. Semnas Ristek (Seminar Nasional Riset Dan Inovasi Teknologi), 5(1).

PRIYANTO, FUAD. (2018). SISTEM INFORMASI PENJUALAN SEPATU TOKO "AAP COLLECTION" DI KROYA MENGGUNAKAN BARCODE SCANNER. UNIVERSITAS MUHAMMADIYAH PURWOKERTO.

Sudirman, Acai, Muttaqin, Muttaqin, Purba, Ramen A., Wirapraja, Alexander, Abdillah, Leon A., Fajrillah, Fajrillah, Arifah, Fatimah Nur, Julyanthry, Julyanthry, Watrianthos, Ronal, \& Simarmata, Janner. (2020). Sistem Informasi Manajemen. 
Perancangan Sistem Informasi Penjualan Handphone di Forza Mufid Perdana Selular

Yayasan Kita Menulis.

Yanuarti, Elly. (2017). Desain Aplikasi Pengelolaan Laboratorium Komputer. Jurnal $\begin{array}{lllll}\text { Sisfokom (Sistem Informasi Dan Komputer), } & 6(1), & 60 .\end{array}$ https://doi.org/10.32736/sisfokom.v6i1.181 